\title{
Thalidomide in plasma cell balanitis refractory to conventional topical treatment ${ }^{*}$
}

\author{
Lucas Mariano Serrão ${ }^{1}$, Karina Demoner de Abreu Sarmenghi ${ }^{1}$, Barbara Christina Bonino Pereira Pinto ${ }^{1}$, \\ Paulo Bittencourt de Miranda ${ }^{2}$
}

DOI: http:/ /dx.doi.org/10.1590/abd1806-4841.20187462

\begin{abstract}
Zoon's plasma cell balanitis is a chronic genital inflammatory dermatosis that affects uncircumcised men, especially the elderly. It's characterized by painless erythematous plaques of orange hue, located on the glans penis and foreskin. Circumcision is the most effective treatment; however, it can be hard for patients to accept. As an alternative, topical calcineurin inhibitors are used, with good response. This article reports the case of a 32-year-old patient, HIV carrier, diagnosed with Zoon's plasma cell balanitis. Treatment with topical tacrolimus was administered, without improvement. A 6-week course of thalidomide resulted in complete remission of the lesions, without recurrence after eight months of follow-up.
\end{abstract}

Keywords: Balanitis; Male urogenital diseases; Thalidomide; Treatment outcome

\section{INTRODUCTION}

Zoon's plasma cell balanitis (ZPB) is a chronic inflammatory genital dermatosis, of unknown etiology, described mostly in older uncircumcised men. ${ }^{1,2}$ Clinically, it is characterized by a single, generally asymptomatic, shiny, reddish or orangey-red plaque located on the glans penis and, less frequently, on the foreskin. ${ }^{2,3}$

Various therapeutic modalities are proposed for ZPB, and circumcision is considered as the most effective option. ${ }^{1-3}$ In an attempt to avoid surgical treatment, topical medications are an interesting option. ${ }^{2}$ Recent studies show good results in patients treated with tacrolimus $0.03 \%{ }^{1,3}$

We report the use of thalidomide in the treatment of $\mathrm{ZPB}$ in a patient with HIV (human immunodeficiency virus), with an undetectable viral load, who lacked improvement using tacrolimus
$0.03 \%$ and $0.1 \%$.

\section{CASE REPORT}

A 32-year-old patient complained of a painless lesion on the glans penis over a period of four months. He had used various medications, including ciprofloxacin, clindamycin, ceftriaxone, levofloxacin, valaciclovir and fluconazole, without improvement. He was HIV positive, with recent reconstitution of immunity (CD4 = 357/ $\mathrm{mm}^{3}$ ) and an undetectable viral load. Under dermatological examination, an erythematous, eroded, moist, poorly defined plaque was found on the glans penis and the foreskin (Figure 1). A biopsy was performed, and the histopathological study showed hyperplasia of the squamous epithelium, without atypia, and intense lymphoplas-

\footnotetext{
Received 01 August 2017.

Accepted 20 January 2018

* Work conducted at Hospital Santa Casa de Misericórdia de Vitória, Vitória (ES), Brasil.

Financial support: None.

Conflict of interest: None.

Dermatology Service, Hospital Santa Casa de Misericórdia de Vitória, Vitória (ES), Brazil.

Department of Dermatopathology, Hospital Santa Casa de Misericórdia de Vitória, Vitória (ES), Brasil.

MaILING AdDREss:

Lucas Mariano Serrão

E-mail: lucasserrao@hotmail.com

(C)2018 by Anais Brasileiros de Dermatologia
} 
macytic infiltrate of the dermis, confirming the diagnosis of Zoon's plasma cell balanitis. Tacrolimus $0.03 \%$ and $0.1 \%$ were used regularly for 10 weeks, without satisfactory response (Figures 2 and $3)$. Due to persistence of the lesion, thalidomide (100mg/day) was prescribed for six weeks, resulting in remission of the disease and no relapse in eight months of follow-up (Figure 4).

\section{DISCUSSION}

ZPB is a benign, chronic inflammatory genital disease that occurs especially in elderly and uncircumcised men, though it can occur at any age. A similar process can affect the genitalia of women. ${ }^{1,2}$

In 1952, Zoon first described this entity in a series of eight cases of men with chronic balanitis and clinical diagnosis of

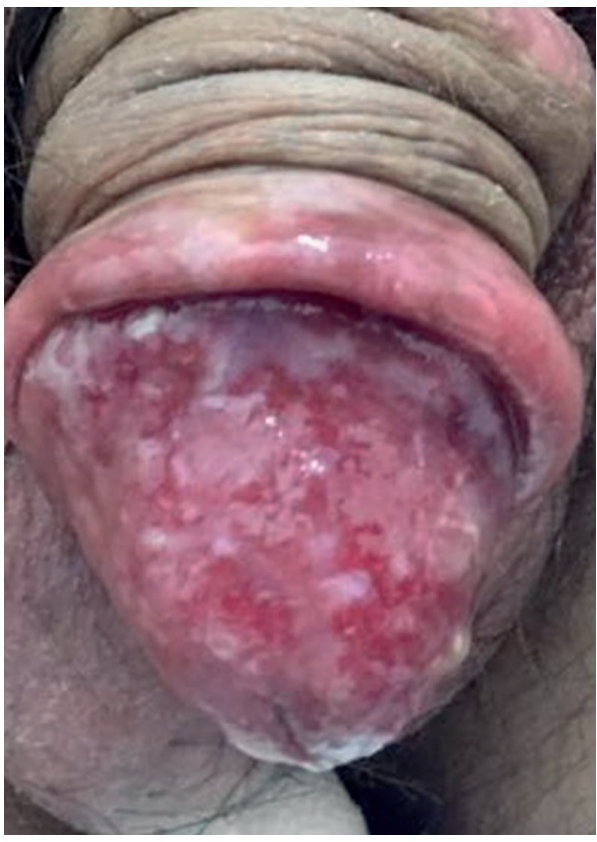

Figure 1: Before treatment.

Bright, moist, poorly delimitated erythematous plaque located on the glans penis and foreskin

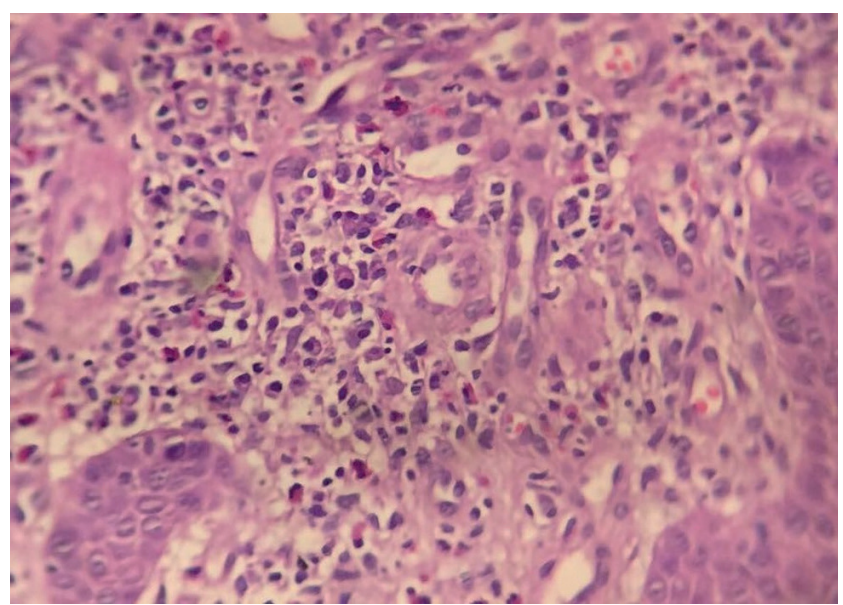

FIGURE 3: Histopathological exam. Lymphocytic infiltrate with some eosinophils and microvascular proliferation (Hematoxylin \& eosin, $\mathrm{x} 40$ )

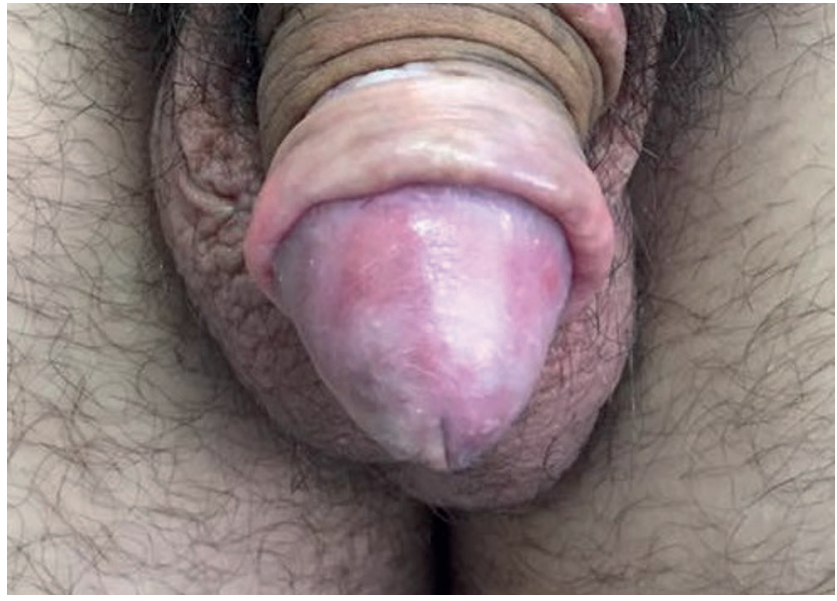

FIGURE 4: After a six-week course of thalidomide. Remission of the lesion with residual erythema

erythroplasia of Queyrat, whose histopathological examination showed a plasmacytic inflammatory process in the dermis, but no signs of malignancy. Zoon named this condition balanoposthite chronique circonscrite bénigne à plasmocytes. ${ }^{3}$

The etiology is unknown, although several unproven predisposing factors are reported: poor hygiene, trauma, chronic irritation, heat, chronic infection with Mycobacterium smegmatis and HPV. ${ }^{1-3}$

The clinical condition is characterized by singular, moist, shiny, orange-toned erythematous plaques located on the glans penis, though they can also appear on the foreskin and in the coronal groove. ${ }^{1-3}$ Multiple red spots can be seen in the base of the lesions, conferring a "cayenne pepper"-speckled appearance, due to micro-hemorrhages and hemosiderin deposits. "Kissing lesions" are typical in the areas in direct contact with the lesions, such as the foreskin and urethral meatus. There can be itching, dysuria, pain 
and a burning sensation in the area, but the lesions are generally asymptomatic. $^{2,3}$

The clinical differentiation between ZPB and other dermatoses is sometimes challenging. In 2006, Kumar et al. developed clinical criteria for the diagnosis: ${ }^{4}$

1) shiny erythematous plaques on the glans penis, the foreskin, or both;

2) lesions evolving over a period longer than three months;

3) absence of lesions suggestive of lichen planus or psoriasis anywhere on the body;

4) poor response to topical therapies (for at least four weeks);

5) absence of infectious diseases, excluded by the Tzanck test, potassium hydroxide, Gram staining and VDRL.

The main clinical differential diagnosis is erythroplasia of Queyrat, a pre-malignant disease that differs from ZPB in histopathology. ${ }^{1}$ Other differential diagnoses are extramammary Paget's disease, lichen planus, traumatic balanitis, contact dermatitis, seborrheic dermatitis, psoriasis, and infectious diseases such as syphilis, candidiasis and herpes. ${ }^{3}$

The histopathology of ZPB shows a slight epidermal thickening, with acanthosis and parakeratosis; in the following stages, there is atrophy of the epidermis, with erosions and light spongiosis. The dermis presents lichenoid lymphocytic infiltrate, with some plasmacytes on the dermal papillae, which is subsequently replaced by a denser plasmocytic infiltrate, still composed of neutrophils, lymphocytes, eosinophils and erythrocytes. This may be associated with siderophages and hemosiderin deposits. In the advanced stage, the upper dermis shows fibrosis in subepidermal slits and plasma cell exceeding $50 \%$ of the inflammatory infiltrate cells. The immunohistochemical study shows that the plasma cells produce primarily immunoglobulin $\mathrm{G}(\mathrm{IgG})$ and, to a lesser extent, IgA and $\operatorname{IgM} .^{5}$

Therapeutically, circumcision is the most effective treatment, but it can be difficult for patients to accept. ${ }^{1}$ Therefore, topical medications, accompanied by the promotion of hygiene, emerge as an interesting option. ${ }^{2,3}$ Topical corticosteroids are most often used, though relapse is common. ${ }^{2}$ Another option is calcineurin inhibitors: tacrolimus $0.03 \%$ and pimecrolimus 1\%. In 2015, Dayal and Sahu showed good results with these medications. ${ }^{3}$ There are also reports of therapeutic success with imiquimod $5 \%$, fusidic acid, dapsone, photodynamic therapy, $\mathrm{CO}_{2}$ laser, and non-ablative erbium YAG laser., ${ }^{2,3}$

Our patient had regularly used tacrolimus $0.03 \%$ and $0.1 \%$, with no improvement. As an alternative, the patient used thalidomide (N-alpha-phthalimidoglutarimide), a synthetic derivative of glutamic acid, whose mechanism of action is not completely understood. The hypotheses include a reduction in the levels of the tumoral necrosis factor (TNF), the inhibition of interleukin-12, and the production and co-stimulation of CD8 lymphocytes, as well as the suppression of the mechanisms of phagocytosis. ${ }^{6,7}$ In the reported case, thalidomide (100mg/day) was used for six weeks, with complete remission of the disease. The patient did not in the following 8 months and remains in follow-up at the dermatology out-patient clinic.

We speculate that thalidomide can be a good option in the treatment of ZPB cases refractory to conventional topical medications. $]$

\section{REFERENCES}

1. Delgado L, Brandt HR, Ortolan DG, Patriota RC, Criado PR, Belda Junior W. Balanite plasmocitária de Zoon: relato de dois casos tratados com pimecrolimo. An Bras Dermatol. 2011;86:35-8.

2. Andrade SMF, Lorenski FR, Pinto DCS, Tebcherani A, Pontes MC. Laser fracionado de $\mathrm{CO} 2$ e ácido fusídico na balanite de Zoon: relato de caso. Surg Cosmet Dermatol. 2012;4:189-91.

3. Dayal S, Sahu P. Zoon balanitis. A comprehensive review. Indian J Sex Transm Dis. 2016;37:129-38.
4. Kumar B, Narang T, Dass Radotra B, Gupta S. Plasma cell balanitis: clinicopathologic study of 112 cases and treatment modalities. J Cutan Med Surg. 2006;10:11-5.

5. Weyers W, Ende Y, Schalla W, Diaz-Cascajo C. Balanitis of Zoon: a clinicopathologic study of 45 cases. Am J Dermatopathol. 2002;24:459-67.

6. Penna GO, Pinheiro AM, Hajjar LA. Talidomida: mecanismo de ação, efeitos colaterais e uso terapêutico. An Bras Dermatol. 1998; 73:501-14.

7. Borges LG, Fröelich PE. Talidomida - novas perspectivas para utilização como antiinflamatório, imunossupressor e antiangiogênico. Rev Assoc Med Bras. 2003;49:96-102.

\section{AUTHORS'CONTRIBUTIONS}

Lucas Mariano Serrão

(iD) ORCID 0000-0003-3467-978X

Approval of the final version of the manuscript, Conception and planning of the study, Elaboration and writing of the manuscript, Obtaining, analyzing and interpreting the data, Intellectual participation in propaedeutic and/or therapeutic conduct of the cases studied

Karina Demoner de Abreu Sarmenghi $\quad$ (iD) ORCID 0000-0002-4039-808X

Approval of the final version of the manuscript, Participação efetiva na orientação da pesquisa, Intellectual participation in propaedeutic and/or therapeutic conduct of the cases studied, Critical review of the literature, Critical review of the manuscript

Barbara Christina Bonino Pereira Pinto $\quad$ (iD) ORCID 0000-0002-6403-1661

Elaboration and writing of the manuscript, Effective participation in research orientation, Intellectual participation in propaedeutic and/or therapeutic conduct of the cases studied, Critical review of the literature, Critical review of the manuscript

Paulo Bittencourt de Miranda $\quad$ (iD) ORCID 0000-0003-0883-4870

Approval of the final version of the manuscript, Conception and planning of the study, Obtaining, analyzing and interpreting the data, Effective participation in research orientation, Critical review of the manuscript

How to cite this article: Serrão LM, Sarmenghi KDA, Pinto BCBP, Miranda PB. Thalidomide in plasma cell balanitis refractory to conventional topical treatment. An Bras Dermatol. 2018;93(6):881-3. 